\title{
Establishing a methodology to study the influence of quercetin on the metabolism of the K562/ADM cell line using nuclear magnetic resonance technology
}

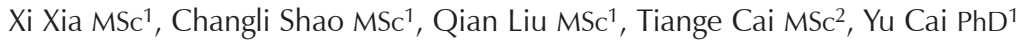

X Xia, C Shao, Q Liu, T Cai, Y Cai. Establishing a methodology to study the influence of quercetin on the metabolism of the K562/ADM cell line on the basis of nuclear magnetic resonance technology. Curr Res Integr Med 2015;1(2):23-25.

The purpose of the present study was to establish an experimental method to study the effects of quercetin on the metabolism of the drug-resistant leukemia cell line K562/ADM using nuclear magnetic resonance (NMR) technology. Drug administration to the cells was performed according to proper experimental design and application. The cells were collected and inactivated by repeated freeze-thaw cycles using liquid nitrogen. Methanol

Metabonomics was initially defined by Nicholson et al (1) in 1999 I and subsequently developed into a discipline that quantitatively describes the endogenous metabolites of an organism and its changes (2). Metabonomics research is based on biological fluids, cell extractions, cell culture fluid and tissues, and often use HPLC, GC, MS, NMR, IR and other technologies for detection (3). Quercetin is a natural polyhydroxy flavonoid that commonly exists in fruit, vegetables and other natural plants. It has general pharmacological action, such as antitumour, antioxidant, anti-inflammatory and antithrombotic properties $(5,6)$, and can reverse the multiple drug resistance of leukemia cells $(7,8)$. Metabolites, which are the material foundation of discovering and identifying biomarkers, play an important role in studying cell metabolism. However, to obtain integral metabolites and comprehensive metabolite profiling analyses, optimal extraction methods are needed. The present study established a convenient methodology for isolating metabolites based on researching the influence of quercetin on the metabolism of the drug-resistant leukemia cell line K562/ADM.

\section{Material, instrumentation and supplier summary}

SW-CJ-IFD clean bench (Sujing Group, Suzhou Antai Air Technology Co, Ltd); SC-04 low speed centrifuge (Anhui Zhongke Zhongiia Science Instrument Co, Ltd); TS100 inverted fluorescence microscope (Nikon, edipse); constant temperature carbon dioxide incubator (Thermo Scientific); SB5200D ultrasonic cleaner (Ningbo Xinzhi Biological Polytron Technologies Inc); ACCULAB one over ten-thousand analytical balance (Beijing Sartorius Instrument System Co, Ltd); LS-50HJ vertical pressure steam sterilizer (Jiangyin Binjiang Medical Equipment Co, Ltd); $500 \mathrm{MHz}$ NMR (Bruker, Germany); cell culture flask (America, Corning); dimethyl sulfoxide (Beijing PuBoXin biotechnology co, Ltd); modified RPMI-1640 culture medium (Gibco); Sijiqing fetal bovine serum (Zhejiang Tianhang Biological Technology Co, Ltd); phosphate-buffered saline (Thermo Fisher biochemical products Beijing Co, Ltd, Beijing, China); penicillin and streptomycin solution (100x, Beyotime Institute of Biotechnology); $\mathrm{D}_{2} \mathrm{O}$,

\begin{abstract}
(80\%) was used to extract cell metabolites, and a sample concentrator (Termovap, ECOM, Czech Republic) was used to purify the samples. All samples were assessed using $500 \mathrm{MHz}$ NMR (Bruker, Germany) with standard NOESY impulse sequence to obtain ${ }^{1} \mathrm{H}$-NMR spectra of cell metabolites. The processing method used to assess cell metabolism established in the present study was convenient and led to minimal loss of cell metabolites. The ${ }^{1} \mathrm{H}-\mathrm{NMR}$ spectra obtained using NMR technology reliably reflected changes in cell metabolism.
\end{abstract}

Key Words: K562/ADM; Metabolism; Methodology; Quercetin

3-(trimethylsilyl)propionic acid sodium salt (Shenzhen, Merrill Chemical Technology Co, Ltd); quercetin API (lot number 2013080601, content $\geq 97.0 \%$, Guangzhou Aichun Pharmaceutical Science and Technology Co, Ltd); K562/ADM cell line (Nanjing Kaiji Biological Technology Development Co, Ltd).

\begin{abstract}
Cell culture
Cells (K562/ADM) were removed from liquid nitrogen storage and quickly placed in a water bath at $37^{\circ} \mathrm{C}$ for thawing, and subsequently transferred to a centrifuge tube for centrifuging at $1000 \mathrm{rpm}$ for $3 \mathrm{~min}$. The supernatant was removed, and $10 \%$ fetal bovine serum (FBS) and $1 \%(\mathrm{v} / \mathrm{v})$ penicillin/streptomycin RPMI culture solution was added to the resuspended cells. K562/ADM cells were transferred to a cell culture flask and mixed using a pipette, then incubated at $37^{\circ} \mathrm{C}$ with $5 \% \mathrm{CO}_{2}$ at a density of $5 \times 10^{4}$ cells $/ \mathrm{mL}$ to $7 \times 10^{4}$ cells $/ \mathrm{mL}$. Recovered cells were transferred into centrifuge tube and centrifuged at $1000 \mathrm{rpm}$ for $5 \mathrm{~min}$. Following removal of the supernatent, the cells were resuspended in fresh medium and transferred into a culture flask followed by incubation at $37^{\circ} \mathrm{C}$ with $5 \% \mathrm{CO}_{2}$.
\end{abstract}

METHODS

\begin{abstract}
Cell passage
Cell passage was performed when cell density reached $\geq 80 \%$. Cells were transferred to a centrifuge tube at $1000 \mathrm{rpm}$ for $5 \mathrm{~min}$ and the supernatent was discarded. Next, the cells were resuspended and washed with phosphate-buffered saline (PBS) solution one to three times. Cells were resuspended in fresh culture medium and transferred into a culture flask at a density of $5 \times 10^{4}$ cells $/ \mathrm{mL}$ to $7 \times 10^{4}$ cells $/ \mathrm{mL}$, then incubated at $37^{\circ} \mathrm{C}$ with $5 \% \mathrm{CO}_{2}$.
\end{abstract}

\section{Cell cryopreservation}

Cell cultures that exhibited good growth were collected in the logarithmic growth phase, centrifuged and counted before cryopreservation . Cell density needed to be controlled at $5 \times 10^{5}$ cells $/ \mathrm{mL}$ to $6 \times 10^{5}$ cells $/ \mathrm{mL}$.

${ }^{1}$ College of Pharmacy, JiNan University, Guangzhou 510632; ${ }^{2}$ Academy of science, Liaoning University, Shenyang 110036, China

Correspondence: Dr Cai Yu, College of Pharmacy, JiNan University, 601 Huangpu Avenue West, Guangzhou, Guangdon 510632, China; Mr Cai

Tiange, Academy of science, Liaoning University, Liaoning, Shenyang, 10036, China. Telephone 8613119582329 , e-mail caiyu8@sohu.com 

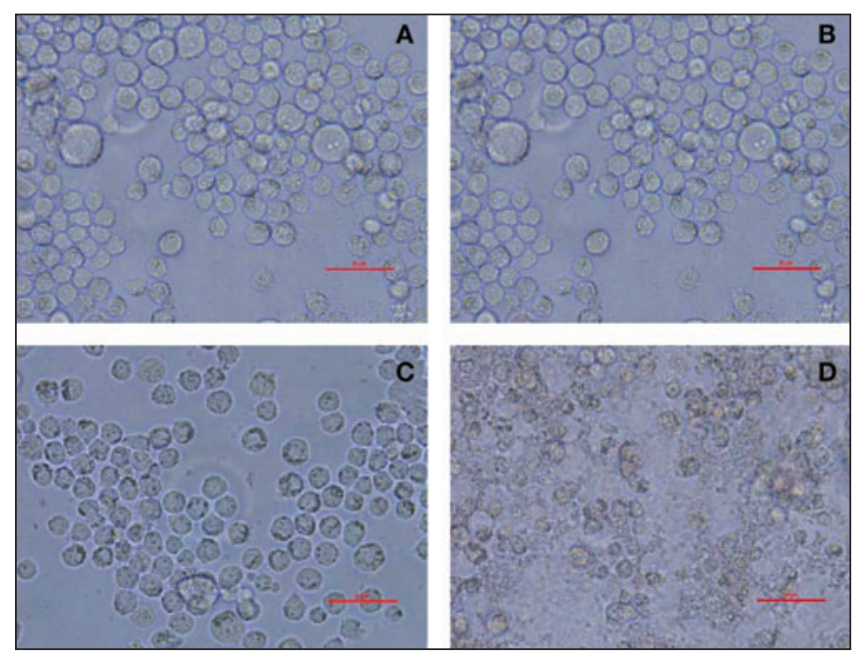

Figure 1) Morphology of K562/ADM cells (original magnification $\times 400$ ). A Blank control group. B Low-dose group. C Medium-dose group. D High-dose group

Next, cells were placed in cell freezing medium (1:9 ratio of DMSO:FBS) and blended; the solution was then stored at $4^{\circ} \mathrm{C}$, $-20^{\circ} \mathrm{C},-80^{\circ} \mathrm{C}$ for $10 \mathrm{~min}, 30 \mathrm{~min}$ and $16 \mathrm{~h}$ to $18 \mathrm{~h}$, respectively. All samples were ultimately placed in liquid nitrogen.

\section{Cell experiment}

K562/ADM cells in the logarithmic growth phase were collected, counted and transferred to a $75 \mathrm{~cm}^{2}$ cell culture flask at a density of $1 \times 10^{5}$ cells $/ \mathrm{mL}$. Samples were divided into four groups according to the final concentration of quercetin used in the experiments: blank control (culture solution with 1:1000 DMSO); low dose $(10 \mu \mathrm{mol} / \mathrm{L})$; medium dose $(20 \mu \mathrm{mol} / \mathrm{L})$; and high dose $(40 \mu \mathrm{mol} / \mathrm{L})$. All of the above were incubated at $37^{\circ} \mathrm{C}$ with $5 \% \mathrm{CO}_{2}$.

\section{Cell collection and processing}

After $72 \mathrm{~h}$ in culture, the cells were centrifuged at $1000 \mathrm{rpm}$ for $5 \mathrm{~min}$ and then collected after washing with PBS three times followed by flash freezing in liquid nitrogen. The cells underwent three freeze-thaw cycles before NMR treatment. Two millilitres of $80 \%$ methanol was added to the samples and blended, and ultrasonication ( $3 \mathrm{~s}$ on/2 s off) was performed while the samples were on an ice bath for $10 \mathrm{~min}$, followed by centrifugation at 12,000 rpm for $15 \mathrm{~min}$. The supernatant was collected and $1 \mathrm{~mL} \mathrm{80 \%} \mathrm{methanol} \mathrm{was} \mathrm{added} \mathrm{to} \mathrm{the} \mathrm{residue.} \mathrm{This} \mathrm{treatment} \mathrm{was}$ repeated twice. The supernatants were then combined and dried using a nitrogen blow down evaporator.

\section{Collection and processing of cell culture fluid}

Cells were centrifuged after culture for $72 \mathrm{~h}$ and the supernatant was collected, of which $3 \mathrm{~mL}$ was obtained for filtering using a $0.22 \mu \mathrm{m}$ filter (Waters, USA). Subsequently, centrifugation was performed at $12,000 \mathrm{rpm}$ for $20 \mathrm{~min}$ followed by storage in liquid nitrogen. Solvent was removed under vacuum and the residue was freeze-dried to obtain freeze-dried powder before NMR treatment.

\section{NMR sample analysis}

Sample preparation: The cell extracts were dissolved in $6 \mathrm{~mL} 0.01 \%$ TMSP/D $/ \mathrm{D}_{2} \mathrm{O}$ solution and centrifuged at $15,000 \mathrm{rpm}$ for $20 \mathrm{~min} ; 0.5 \mathrm{~mL}$ of supernatant was placed in an NMR tube and kept cold for analysis.

\section{NMR detection}

All ${ }^{1} \mathrm{H}$-NMR spectra were generated using $500 \mathrm{MHz}$ NMR (Bruker, Germany) with a $5 \mathrm{~mm}$ probe. A standard NOESY impulse sequence was used to obtain spectra of the cell extracts. In this pulse sequence, wait time (RD, $2 \mathrm{~s}$ ) and mixing time (tm $0.1 \mathrm{~s}$ ) was conducted water peak suppression. Related parameters were set as follows: $\mathrm{SWH}, 12 \mathrm{kHz}$;

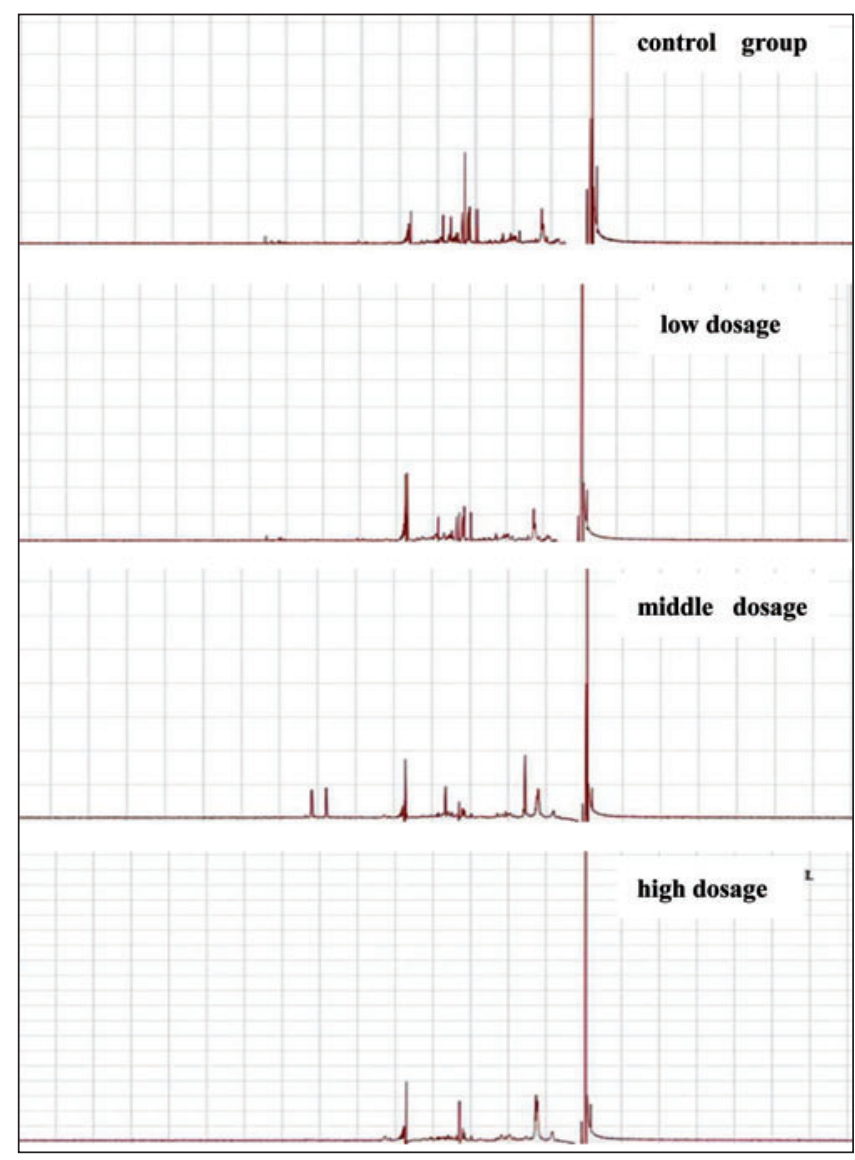

Figure 2) ${ }^{1} \mathrm{H}-\mathrm{Nuclear}$ magnetic resonance spectra

sampling time, 1.36 s; TD, 32768; NS, 64. All FID signals of ${ }^{1} \mathrm{H}-\mathrm{NMR}$ were multiplied by an exponential window function whose broadening factor was $0.5 \mathrm{~Hz}$ before Fourier transform.

\section{RESULTS}

Morphological observation of K562/ADM cells

Cellular morphology of the K562/ADM cells after treatment with quercetin for $72 \mathrm{~h}$ was assessed under reverse microscopy (original magnification $\times 400$ ) (Figure 1).

As shown in Figure 1, the cellular shape of the blank control group (1:1000 DMSO) is high-blooded without shrinkage or cracking. No significant difference was observed compared with pretherapy. However, in the low-dose group ( $10 \mu \mathrm{mol} / \mathrm{L}$ quercetin), a small number of cells had ruptured and exhibited lower activity. In the high-dose group ( $40 \mu \mathrm{mol} / \mathrm{L}$ quercetin), the phenomenon of cell shrinkage and rupture was obvious. Thus, it was educible that quercetin could inhibit the growth of K562/ADM in a dose-dependent manner.

\section{NMR assessment of cell extracts}

NMR assessment was conducted as described, and the results obtained underwent Fourier transform to obtain ${ }^{1} \mathrm{H}-\mathrm{NMR}$ spectra, which were then conducted phase calibration and baseline adjustment. Chemical displacement of all spectra was calibrated with TMSP $(\delta=0.00)$. TMSP-marked peaks were obvious in the four ${ }^{1} \mathrm{H}$-NMR spectra. There was apparent characteristic peak and high peak value, as shown in Figure 2.

\section{DISCUSSION}

Drug-resistant K562/ADM cells were cultured in $1000 \mathrm{ng} / \mathrm{mL}$ adriamycin medium to maintain drug resistance (9). To avoid the influence of adriamycin on the results, K562/ADM cells should be cultured in a normal culture medium without adriamycin for two 
weeks before the experiment. Two weeks later, K562/ADM cells should be placed into culture solution containing adriamycin so as to maintain drug resistance.

The process of cell collection and processing was implemented after treatment with quercetin for $72 \mathrm{~h}$. The present study vacuum freeze-dried the cell extracts by repeated freezing and thawing the cell extract three times to inactivate the cells, then an $80 \%$ methanol solution was added to extract the intracellular metabolites; the collected metabolite solutions were subsequently freeze dried to powder form. However, this method required a lyophilizer to remove organic solvent, which required specialized equipment and not easy to conduct. Therefore, a nitrogen blow down evaporator was ultimately chosen for drying the samples.

There have been many detection technologies used in metabonomics research includiung HPLC, MS and GC. The present study chose NMR for the following advantages (10-12): Pre-treatment of samples was easy and the required detection amount was small.

\section{REFERENCE}

1. Nicholson JK, Lindon JC, Holmes E. 'Metabonomics':understanding the metabolic responses of living systems to pathophysiological stimuli via multivariate statistical analysis of biological NMR spectroscopic data. Xenobiotica 1999;29:1181-9.

2. Tang HR, Wang YL. Metabonomics: A revolution in progress. Prog Biochem Biophys 2006;33:401-17.

3. Lenz EM, Wilson ID. Analytical strategies in metabonomics. J Proteome Res 2007;6:443-58.

4. Sun J, Yu S. Research progress of quercetin. Research and Practice on Chinese Medicines 2011;3:85-8.

5. Han Y, Cao L, Hao H, et al. Study of quercetin reverses the expression of multidrug resistance in leukemia cell line K562/A and the related genes. J Exp Hematol 2011;4:884-9.

6. Liu M, Xiao Y, Zuo A, et al. The research of Quercetin, phloretin, silybin scavenge free radicals and inhibit lipid peroxidation activity. Chinese patent medicine 2012;4:753-6.

7. Shu Y, Tan T, Zhang S, et al. Progress in pharmacological research of quercetin. West China J Pharmaceutical Sci 2008;6:689-91.
Detection could be performed as soon as $\mathrm{D}_{2} \mathrm{O}$ was added for field lock and special treatment of the samples was unnecessary. The structure and original properties of the samples were not destroyed; detection time is short (approximately $5 \mathrm{~min}$ to $10 \mathrm{~min}$ ); and sample purification was not necessary. Meanwhile, various two-dimensional spectroscopy could be used for the determination and structural identification of unknown metabolites.

DISCLOSURES: The authors have no financial disclosures or conflicts of interest to declare.

FOUNDATION SUPPORT: The General Program of the National Natural Science Foundation of China (NO. 81173215). The ministry of education in the new century excellent talents to support plan (NO. NECT-12-0677). Guangzhou science and technology cooperation platform project (2014J4500005).

8. Chen C, Cai T, Zhang R, et al. Effects of 6 kinds of active ingredients of Chinese herbal medicine on reversing drug resistance of K562/ADM and P27 , P170 protein expression. Chinese Patent Medicine 2014;1:1-4.

9. Gai X, Li C, Li Q, et al. Reversal effect of saikosaponin on human leukemia cell line K562/ADM in multidrug resistance in vitro. Chin J Pathophysiol 2012;1:76-80.

10. Wang weiguang,Yu guangqing,Zhang guoyan,et al. Quercetin reverses multidrug resistance on K562/ADM in vitro. Heilongjiang Medicine and Pharmacy 2011;34:28-9.

11. Miao C,Wang Y. Application of NMR technique in the discovery and pharmacological studies of active substances from natural products. Acta Pharmaceutica Sinica 2013;48:1383-9.

12. Zou Y, He J, Xie H,et al. Application of metabolic studies in animal nutrition on the basis of NMR technology. Chin J Animal Nutr 2012;24:2073-8. 